\title{
DE VERDWENEN BEELDJES VAN PRAMBANAN
}

In 1947, enkele weken nadat ik als parttime assistent-conservator in dienst van het Museum van Aziatische Kunst was getreden, vertrok de conservator Herman Visser voor een studiereis van zes maanden naar Amerika. Hij vroeg Theodoor van Erp, de vice-voorzitter van de Vereniging van Vrienden der Aziatische Kunst, tijdens zijn afwezigheid het conservatorschap waar te nemen, een taak die de toen 73-jarige Van Erp bereidwillig op zich nam.

Kort na Vissers vertrek installeerde van Erp zich in het bureau van het museum. Hij nam meteen zijn tekentafel mee en bracht het grootste deel van zijn tijd door met het natekenen van de foto's van dieren- en vogelmedaillons van Candi Panataran van de Oudheidkundige Dienst. Van Erp bekommerde zich maar weinig om de dagelijkse gang van zaken in het museum. Al tekenend vertelde hij mij op boeiende wijze hoe hij bijna vijf jaar lang (19061911 ) met zijn familie in de pasanggrahan aan de voet van de Borobudur had gewoond, dag in dag uit leiding gevend aan het omvangrijke restauratiewerk op wat hij de 'oude grijze stoepa' noemde. Zijn diepe respect voor de integriteit van het monument, zijn zeldzame affiniteit met de intenties van de architecten en beeldhouwers, en zijn levendige beschrijving van de avontuurlijke jacht op losse bouwstenen in de omliggende desa's maakten een diepe indruk op mij. Mijn interesse was gewekt en het volgende jaar ging ik dan ook in Leiden de colleges in de Indonesische archeologie van professor F.D.K. Bosch volgen. Sindsdien is de Borobudur nooit ver uit mijn gedachten geweest.

Op zekere dag onderbrak Van Erp zijn fascinerende monoloog en maakte zo langs zijn neus weg een interessante opmerking. Een paar jaar geleden, zo zei hij, had hij toevallig ergens in een tuin in Blaricum, waar hij tijdens de oorlog zijn toevlucht had gevonden, een paar stenen beeldjes van Prambanan zien staan. Daar hij zich niet meer precies kon herinneren waar, stelde hij mij voor eens op de fiets in de buurt op onderzoek uit te gaan. Het volgend weekend toog ik eropuit, maar hoe ik ook zocht, het is me niet gelukt de leeuwtjes op te sporen. Eerst veel later heb ik pas begrepen dat Van Erp met zijn suggestie een bedoeling had gehad. Hij dacht van Vissers afwezigheid gebruik te maken om de leeuwtjes voor het museum aan te kopen, maar van dat plan kwam niets terecht.

Meer dan 40 jaar later, in 1978, kwam de herinnering aan dit lang vergeten voorval plotseling weer bij mij boven toen een paar maanden voor mijn pensionering als directeur van Museum of Fine Arts in Boston de conservator voor Chinese kunst, Tom $\mathrm{Wu}$, mij een Nederlandse veilingcatalogus liet zien. Daarin stonden twee leeuwtjes van het Lara Jonggrang-complex van

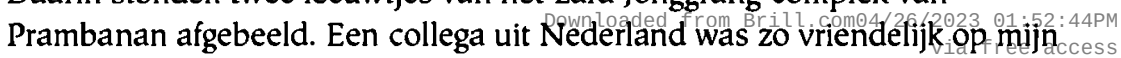




\section{Afbeelding 1}

Leeuw, andesiet, h. 54 cm., afkomstig van de Shiva-tempel van Prambanan, Midden-Java, Museum of Fine Arts, Boston, gift of John Goelet, Constance B. and Carroll L. Cartwright by exchange. Foto courtesy Museum of Fine Arts, Boston

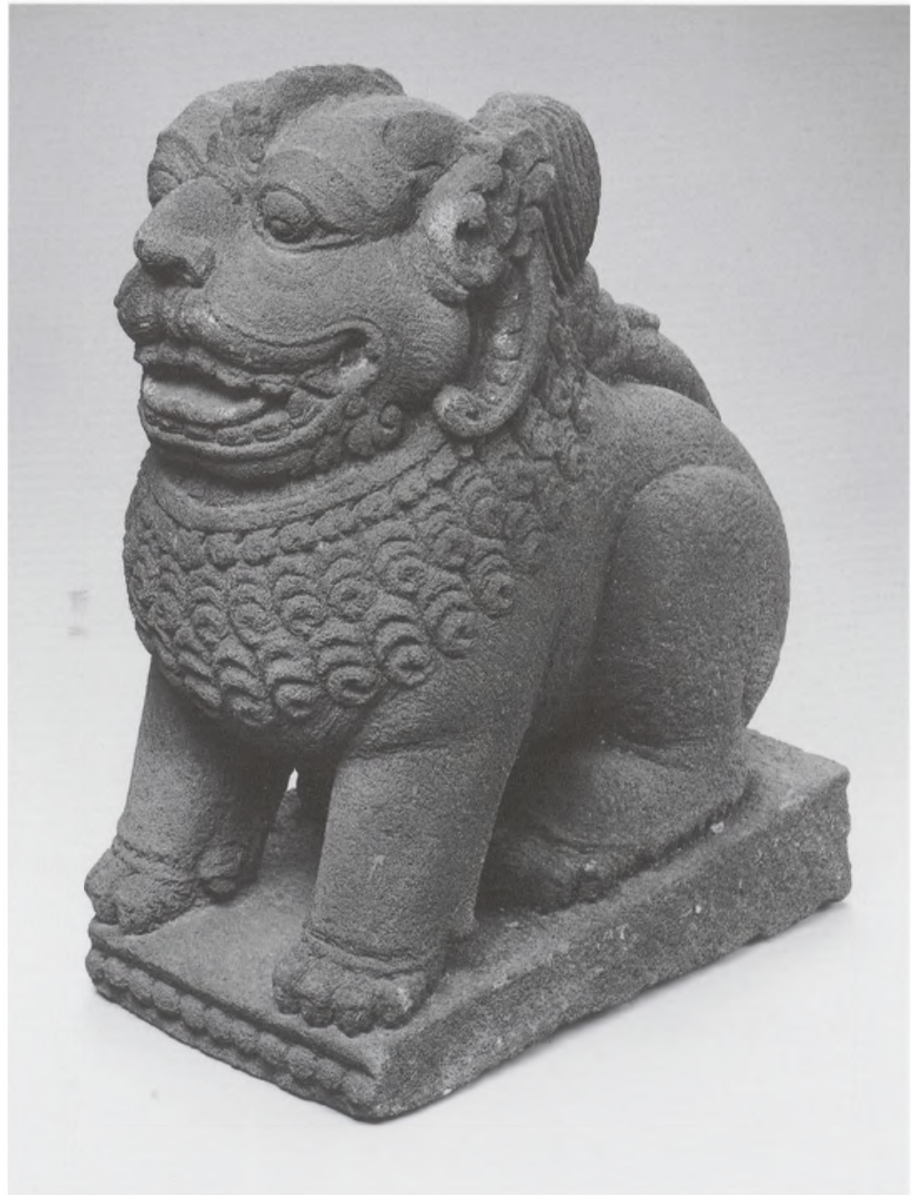

verzoek op de kijkdag van de veiling de twee beelden aan een nader onderzoek te onderwerpen. Beide stukken toonden duidelijk sporen van een groene patina, kennelijk een gevolg van de langdurige blootstelling aan het Nederlandse regenweer. Het lag daarom voor de hand te veronderstellen dat dit inderdaad dezelfde stukken waren als die welke Van Erp meer dan 40 jaar geleden in Blaricum had zien staan, maar die ik niet had kunnen terugvinden. Bij de aankoop van kunstwerken wordt ons maar zelden in ons leven een tweede kans geboden en ik aarzelde dan ook niet die kans te grijpen. Zo werd een van de twee leeuwtjes - het onbeschadigde exemplaar - dat mij als eerste kunstaankoop van mijn leven was ontkomen, nu de laatste in mijn carrière als museumdirecteur (afb. 1).

De klassieke Sanskrit literatuur kent vele verhalen waarin leeuwen een rol spelen, maar zelfs in India, waar de leeuw inheems is, hadden waarschijnlijk maar weinig kunstenaars de gelegenheid de koning der dieren in levende lijve te aanschouwen. Deze omstandigheid kan het proces van de geleidelijke stereotypering van het magistrale dier alleen maar hebben versneld. Zelfs op het beroemde leeuwenkapiteel van Sarnath ( $3^{\mathrm{e}}$ eeuw v.Chr.), dat tot Indiaas nationale symbool is geworden, kunnen wij al de eerste symptomen van dit heraldieke verstarringsproces waarnemen. Het valt echter te betwijfelen of de Javaanse beeldhouwers ooit een levend exemplaar gezien hebben. Wat de Javanen van India erfden, waren dan ook leeuwen van een gestileerde $e_{\text {free }}$ access 


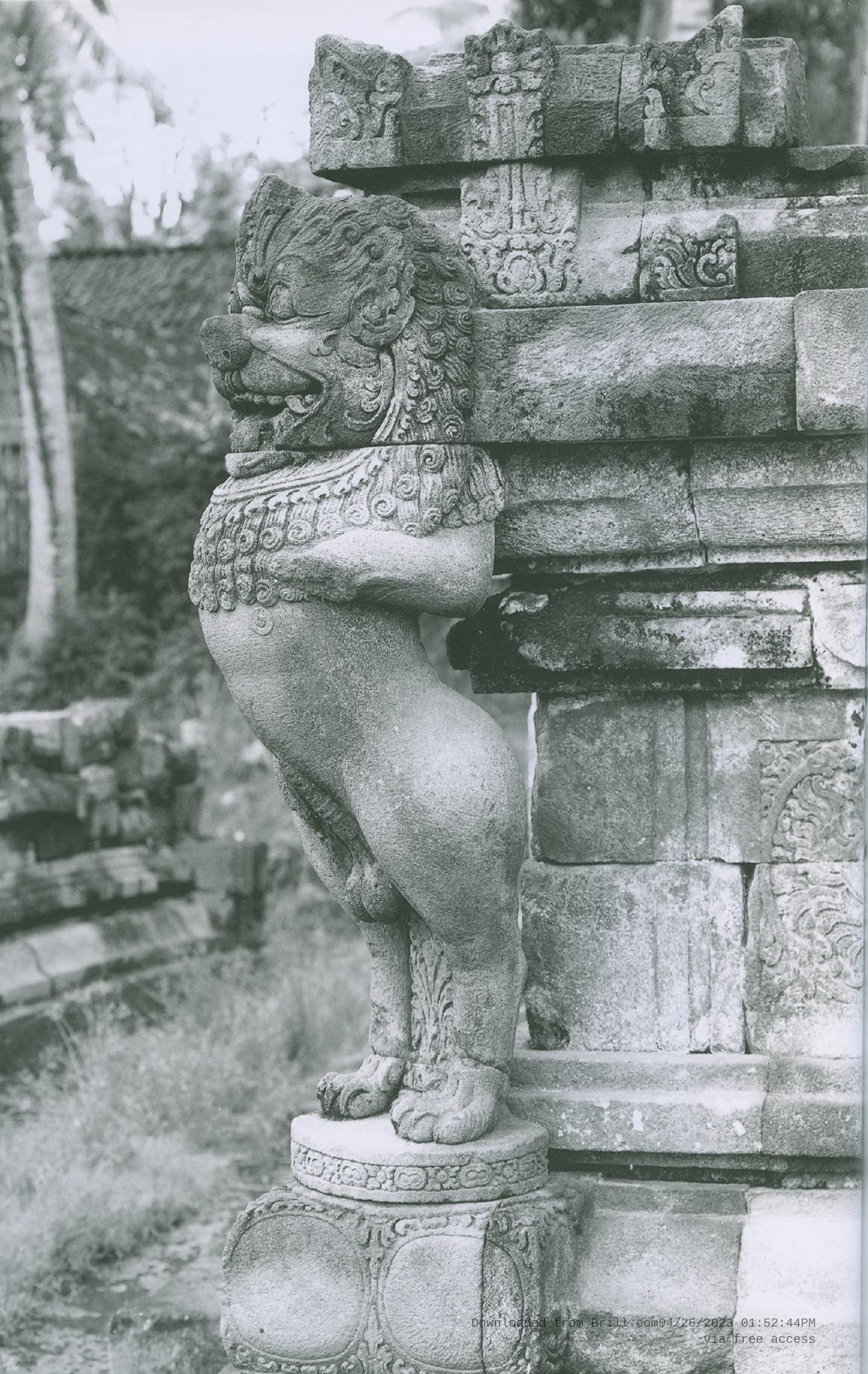


Afbeelding 2 Spuier in de vorm van een steigerende leeuw, Candi Ngawen, MiddenJava. Foto Dirk Bakker

heraldieke soort. De onbekendheid van de beeldhouwers met de levende werkelijkheid blijkt duidelijk uit het feit dat zij het onderscheid tussen leeuwen en leeuwinnen niet kenden en beide met dezelfde, op een ouderwetse kanten kraag lijkende gestileerde manen uitbeeldden. Zo zien wij op de Borobudur dat wanneer Maitreya tot de dieren predikt en allerlei diersoorten paarsgewijs onder zijn toehoorders plaatsnemen, de leeuw en leeuwin identiek worden uitgebeeld. ${ }^{1}$

In het boeddhisme speelt de leeuw eveneens een belangrijke rol. Niet voor niets wordt de historische Boeddha de 'Leeuw van de Sakya-clan' genoemd en is het gebrul van de leeuw een metafoor voor de eerste prediking in het hertenpark in Benares. Op de reliëfs van Borobudur worden vrijwel alleen de Boeddha zelf of de grote bodhisattva's Avalokiteshvara, Maitreya en Samantabhadra zittend op een leeuwentroon (simhasana) uitgebeeld. Maar niet alleen de tronen van de beelden, zelfs hele tempels werden op Java door beelden van leeuwen bewaakt. Op de Borobudur flankeren leeuwen de trappen van de ingangspoorten. De omgang van een van de tempels van het complex van Candi Ngawen (bij Muntilan, Midden-Java) wordt op de vier hoeken door steigerende leeuwen bewaakt. Die vormen niet alleen een symbolische afweer tegen kwade invloeden, maar fungeren tegelijkertijd als spuiers voor het gehele gebouw (afb. 2). Door hun gapende muilen stroomt het regenwater van de omgang in de omringende gracht. Er moeten vroeger op zijn minst nog twee andere tempels van dit type hebben bestaan. Een ervan, vlakbij Candi Lara Jonggrang gelegen, werd door de plaatselijke bevolking Candi Singha of 'Leeuwentempel' genoemd, maar de stenen van dit gebouw zijn in de loop van de $19^{\mathrm{e}}$ eeuw spoorloos verdwenen.

Wij zouden de merites van het leeuwtje van Candi Lara Jonggrang, dat nu ietwat eenzaam op een piëdestal in de hoek van de zaal voor ZuidoostAziatische beeldhouwkunst in het Museum of Fine Arts in Boston staat, waarschijnlijk nog meer waarderen wanneer het dier in zijn oorspronkelijke habitat zou kunnen worden tentoongesteld. Zijn plaats van herkomst is namelijk een nis die de centrale focus vormt van een decoratief schema dat door Van Erp al in zijn eerste studie over Candi Lara Jonggrang het 'Prambanan-motief' wordt genoemd (afb. 3). De wetenschap dat zo weinig van het beeld zichtbaar zou blijven wanneer het in zijn nis was geplaatst, heeft de beeldhouwer er niet van weerhouden alle details van het stuk uit te werken. ${ }^{2}$ Zijn puilogen, de prominente, menselijke neus en de grijns die beide rijen tanden ontbloot, geven hem een goedaardig voorkomen. De voorpoten, ongearticuleerd als die van een speelgoeddier, steunen op een schuin oplopend voetstuk dat aan de voorzijde met een parelrand is afgezet (afb. 1).

De torens van de drie nu gereconstrueerde hoofdtempels van het Prambanan-complex, gewijd aan de hindoegoden Shiva, Brahma en Vishnu, en de drie er tegenover liggende secondaire tempels rijzen alle op van met het Prambanan-motief versierde voetstukken. In de drie grote tempels wordt het middelpunt van dit motief gevormd door een diepe, rechthoekige nis waarin een sculptuur van een leeuw is geplaatst. De nissen worden omlijst door het klassieke torana-motief, bekroond door een monsterkop die door ranken is verbonden met een paar makara of vis-olifanten, het geheel gebeeldhouwd in diverse stadia van stilering. Reliëfs van hemelbomen flankeren de nissen. 


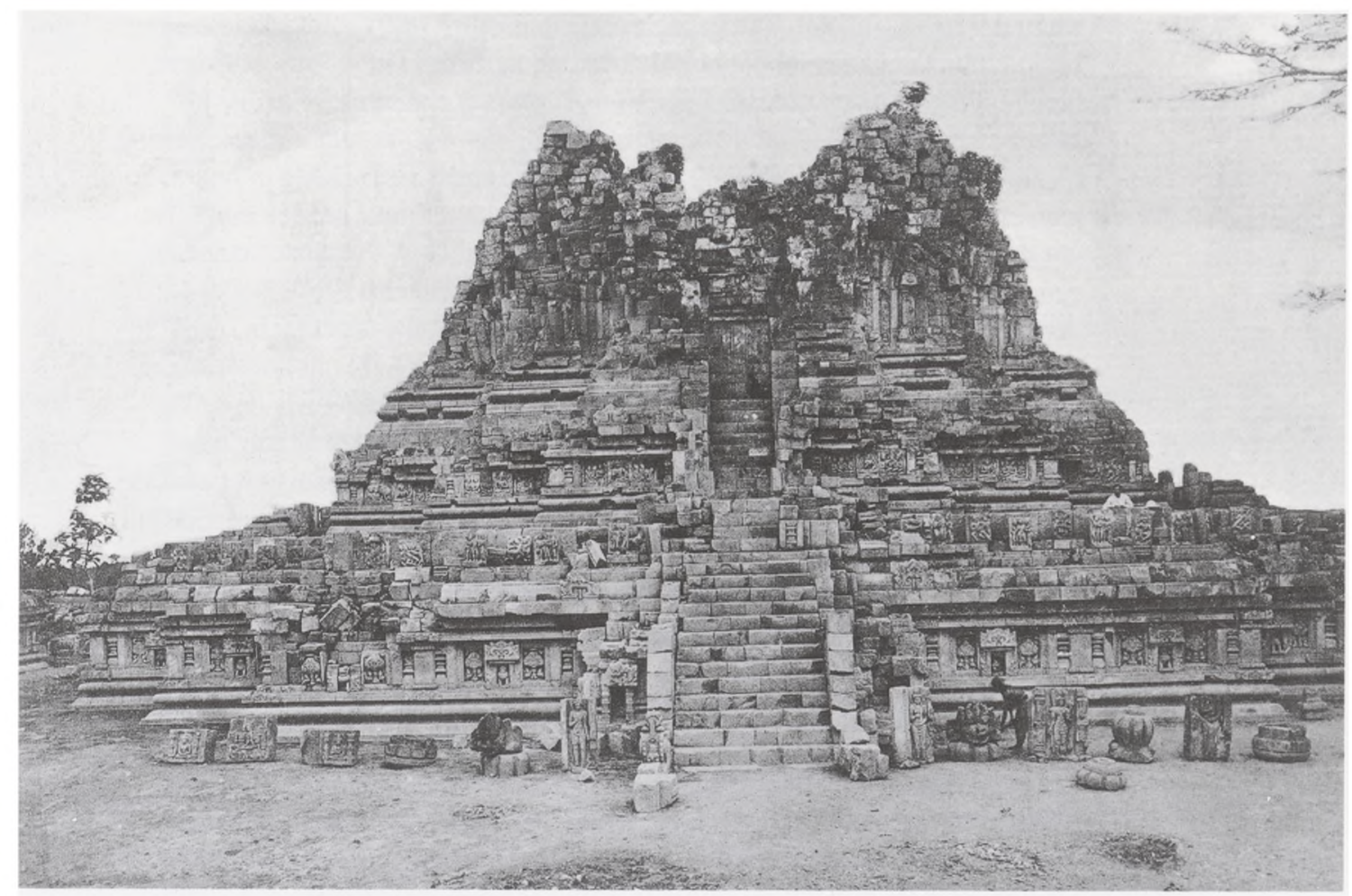

Afbeelding 4 De Shiva-tempel van Prambanan, 1893. Foto Kassian Cephas. Naar J. Groneman, Tjandi Prambanan op Middenlava na de ontgraving, Yogyakarta, 1893
De afmetingen van de nissen en de leeuw (h. $54 \mathrm{~cm}$.) maken duidelijk dat de oorspronkelijke plaats van herkomst van ons leeuwtje alleen een van de nissen van de Shiva-tempel kan zijn geweest. De foto's van Cephas tonen aan dat in 1893 de nissen 13, 21 en 24 leeg waren. Nis 14, die nu ook leeg staat, is op geen enkele foto van Cephas zichtbaar. Duidelijk is dat sedert 1893 op zijn hoogst vier of vijf leeuwtjes verdwenen zijn. De foto's tonen niet voldoende details om te kunnen vaststellen of ons leeuwtje vóór of na 1893 is verwijderd. Wat verder de situatie vrijwel onoplosbaar maakt, is dat de vergelijking van de foto's van Cephas met de huidige toestand aantoont dat sommige leeuwtjes zijn verplaatst, waarschijnlijk om de meest in het oog vallende leemtes, de nissen die de trappen flankeren, met beelden te vullen.

Van Erp, die de tempels van Prambanan grondig had bestudeerd en wiens gedetailleerde rapporten over Prambanan de grondslag voor de latere restauratie hebben gelegd, opperde destijds op mijn vraag een verklaring voor het verdwijnen van deze leeuwtjes. Hij veronderstelde dat de Oudheidkundige Vereeniging van Yogyakarta, als altijd slecht bij kas, wel eens een paar exemplaren als 'duplicaten' van de hand zou kunnen hebben gedaan. Uit de jaarverslagen van die vereniging blijkt dat niet duidelijk. In één ander geval dat ik later ontdekte - het bezoek van koning Chulalongkorn van Siam in 1896 - was sprake van de 'verkoop' van kunstwerken. Koning Chulalongkorn bracht een bezoek aan Prambanan en schonk bij die gelegenheid een gift in geld aan de (straatarme) Archaeologische Vereeniging van Yogyakarta.

Terwijl er later veel ophef is gemaakt van het feit dat hij overal waar hij kwam fraaie stukken uitzocht om mee te nemen naar Bangkok (overigens met medeweten en toestemming van de gouverneur-generaal), is geen melding gemaakt van de koninklijke bijdrage in geld. De koning verkeerde ongetwijfeld in de access 
waan dat hij de stukken had gekocht. Bij zijn bezoek aan Candi Mendut besloot hij overigens niet om de drie beelden in de cella te vragen - dat leek hem te onbescheiden. Zo werd een catastrophe voorkomen! De gang van zaken doet vermoeden dat de betaling voor de Ramayana-reliëfs die de koning bij zijn bezoek verwierf, als 'gift' werd geboekt zonder vermelding in het jaarverslag van de geleverde tegenprestatie. Dit koninklijke bezoek aan Java, dat met een groòtscheepse uitvoer van Midden- en Oost-Javaanse sculptuur gepaard ging, heeft heel wat pennen in beweging gebracht. Wat bij alle verontwaardiging aan Nederlandse zijde nooit ter sprake is gebracht, is dat in de archieven in Bangkok uitvoerige documentatie over het koninklijke bezoek aan Indonesië berust dat een totaal ander licht werpt op deze reis en op de omstreden uitvoer van kunstwerken. Helaas kon door het vroegtijdig overlijden van mijn collega en vriend prins M.C. Subhadradis Diskul een plan om de Thai visie op deze gebeurtenissen te publiceren niet worden verwezenlijkt. Een definitieve opinie over de controverse zal moeten wachten op een vertaling van de stukken in de archieven in Bangkok. Overigens zijn de Prambananreliëfs later door toedoen van Bosch geruild voor een bij Singosari gevonden sculptuurfragment dat op het Ganesha-beeld in Bangkok bleek te passen.

De gang van zaken tijdens het bezoek van koning Chulalongkorn maakt Van Erps vermoeden van soortgelijke transacties met andere gegadigden heel plausibel. Voor het Prambanan-leeuwtje in Boston is er evenwel ook een andere, minder onschuldige mogelijkheid, waarop Jaap Polak mij attent maakte. Het Oudheidkundig Verslag over 1913 bevat het volgende bericht: 'Een ernstig feit bleek zich te hebben voorgedaan bij den grooten Civa-tempel te Prambanan zelf. Bij zijn eerste controle van dit bouwwerk aan de hand der vroeger opgemaakte lijsten, bevond de nieuwe opzichter, dat sinds het bezoek van den Heer Sell in 1912 aan de achterkant (Ganeca-zijde) van den tempel twee leeuwen verdwenen waren, respectievelijk uit de vakken 3 en 23 , terwijl bij een derde sporen werden aangetroffen, dat men eveneens bezig geweest was dien los te werken. De daders zijn waarschijnlijk over den naar de rivierzijde gekeerden, van de opzichterswoning afgewenden muur gekomen, zoodat wellicht daar een meer doeltreffende afsluiting van het terrein aan dien kant dergelijke feiten voor het vervolg te voorkomen zouden zijn.' 5

Van Erp heeft het Museum of Fine Arts slechts eenmaal bezocht, op doorreis naar zijn zoon in Cleveland, en hij heeft over dit bezoek voor onze leden een interessant artikel geschreven in het Maandblad voor Beeldende Kunsten. ${ }^{6}$ Ik kan mij levendig zijn typisch zachtmoedig verraste gelaatsuitdrukking voor de geest halen als hij zijn lang uit het oog verloren leeuwtje daar zou hebben kunnen terugzien.

\section{Noten}

1. Reliëf III-7.

2. Zie over de beeldjes ook P. Lunsingh Scheurleer, 'Elegante topstukjes', Aziatische Kunst 38/3 (2008), pp. 37-43.

3. Pertemuan Ilmiah Arkeologi IV, Yogyakarta, 1989, pp. 334-346.

4. J. Fontein, Het goddelijk gezicht van Indonesië; meesterwerken der beeldhouwkunst 700-1600, Zwolle, 1992.

5. Tweede kwartaal 1913, p. 31.

6. Jaargang 20 (1943), pp. 33-36. 